\title{
Publisher Correction: Coupling of ocean redox and animal evolution during the Ediacaran-Cambrian transition
}

\author{
Dan Wang ${ }^{1,2}$, Hong-Fei Ling ${ }^{2}$, Ulrich Struck ${ }^{3,4}$, Xiang-Kun Zhu' ${ }^{1}$ Maoyan Zhu ${ }^{5,6}$, Tianchen He ${ }^{7}$, \\ Ben Yang 8 , Antonia Gamper ${ }^{3,4}$ \& Graham A. Shields (1) ${ }^{9}$
}

Correction to: Nature Communications https://doi.org/10.1038/s41467-018-04980-5; published online: 03 July 2018

The original version of this Article incorrectly gave the second address in the list of affiliations as "State Key Laboratory of Palaeobiology and Stratigraphy \& Center for Excellence in Life and Paleoenvironment, Nanjing Institute of Geology and Palaeontology, Chinese Academy of Sciences, 210008 Nanjing, China", instead of the correct 'State Key Laboratory for Mineral Deposits Research, School of Earth Sciences and Engineering, Nanjing University, Nanjing 210023, China". This has been corrected in both the PDF and HTML versions of the Article.

Published online: 20 August 2018

Open Access This article is licensed under a Creative Commons Attribution 4.0 International License, which permits use, sharing, adaptation, distribution and reproduction in any medium or format, as long as you give appropriate credit to the original author(s) and the source, provide a link to the Creative Commons license, and indicate if changes were made. The images or other third party material in this article are included in the article's Creative Commons license, unless indicated otherwise in a credit line to the material. If material is not included in the article's Creative Commons license and your intended use is not permitted by statutory regulation or exceeds the permitted use, you will need to obtain permission directly from the copyright holder. To view a copy of this license, visit http://creativecommons.org/licenses/by/4.0/.
\end{abstract}

(C) The Author(s) 2018

\footnotetext{
${ }^{1}$ MNR Key Laboratory of Isotope Geology, MNR Key Laboratory of Deep-Earth Dynamics, Institute of Geology, Chinese Academy of Geological Sciences, 100037 Beijing, China. ${ }^{2}$ State Key Laboratory for Mineral Deposits Research, School of Earth Sciences and Engineering, Nanjing University, Nanjing 210023 , China. ${ }^{3}$ Museum für Naturkunde, Leibniz Institute for Evolution and Biodiversity Science, 10115 Berlin, Germany. ${ }^{4}$ Department of Earth Sciences, Freie Universität Berlin, Malteserstrasse 74-100, Haus D, 12249 Berlin, Germany. ${ }^{5}$ State Key Laboratory of Palaeobiology and Stratigraphy, Center for Excellence in Life and Paleoenvironment, Nanjing Institute of Geology and Palaeontology, Chinese Academy of Sciences, 210008 Nanjing, China. ${ }^{6}$ College of Earth Sciences, University of Chinese Academy of Sciences, 100049 Beijing, China. ${ }^{7}$ School of Earth and Environment, University of Leeds, Leeds LS2 9JT, UK. ${ }^{8}$ MNR Key Laboratory of Stratigraphy and Palaeontology, Institute of Geology, Chinese Academy of Geological Sciences, 100037 Beijing, China.

${ }^{9}$ Department of Earth Sciences, University College London, Gower Street, London WC1E 6BT, UK. Correspondence and requests for materials should be addressed to D.W. (email: njuwangdan@gmail.com) or to H.-F.L. (email: hfling@nju.edu.cn)
} 